\title{
Multiple joint involvement in total knee replacement for osteoarthritis - effects on patient-reported outcomes
}

\begin{tabular}{|r|l|}
\hline Journal: & Arthritis Care and Research \\
\hline Manuscript ID: & ACR-11-0754 \\
\hline Wiley - Manuscript type: & Original Article \\
\hline Complete List of Authors: & $\begin{array}{l}\text { Perruccio, Anthony; Toronto Western Hospital, Arthritis Program and } \\
\text { Division of Orthopaedic Surgery } \\
\text { Power, J. Denise; University of Toronto, Public Health Sciences } \\
\text { Evans, Heather; University of Toronto, Pharmacy } \\
\text { Mahomed, Safiyyah; McMaster University, Health Sciences } \\
\text { Gandhi, Rajiv; Toronto Western Hospital, Arthritis Program and Division of } \\
\text { Orthopaedic Surgery } \\
\text { Mahomed, Nizar; Toronto Western Hospital, Arthritis Program and Division } \\
\text { of Orthopaedic Surgery } \\
\text { Davis, Aileen; Toronto Western Research Institute, Division of Health Care } \\
\text { and Outcomes Research and Arthritis and Community Research and } \\
\text { Evaluation Unit }\end{array}$ \\
\hline Key Words: & Arthroplasty, Osteoarthritis, Psychological Status, Physical Function, Pain \\
\hline \multicolumn{2}{|c}{} \\
\hline \multicolumn{2}{|c}{} \\
\hline \multicolumn{2}{|c|}{} \\
\hline \multicolumn{2}{|c|}{}
\end{tabular}


Multiple joint involvement in total knee replacement for osteoarthritis - effects on patientreported outcomes

Perruccio AV, $\mathrm{PhD}^{1}$, Power JD, MHSc ${ }^{2}$, Evans $\mathrm{HMK}^{3}$, Mahomed $\mathrm{SR}^{4}$, Gandhi R, MD, MSc ${ }^{5}$, Mahomed NN, MD, DSc ${ }^{5}$, Davis $\mathrm{AM}, \mathrm{PhD}^{6}$

1. Division of Orthopaedic Surgery and The Arthritis Program, Toronto Western Hospital, Toronto, Canada; Department of Health Policy, Management and Evaluation, University of Toronto, Toronto, Canada.

2. Division of Health Care and Outcomes Research, Toronto Western Research Institute; Dalla Lana School of Public Health, University of Toronto, Toronto, Canada.

3. Faculty of Pharmacy, University of Toronto, Toronto, Canada.

4. Faculty of Health Sciences, McMaster University, Hamilton, Canada.

5. Division of Orthopaedic Surgery and The Arthritis Program, Toronto Western Hospital, Toronto, Canada; Division of Orthopaedic Surgery, University of Toronto, Toronto, Canada.

6. Division of Health Care and Outcomes Research, Toronto Western Research Institute; Departments of Rehabilitation Science and Health Policy, Management and Evaluation, University of Toronto, Toronto, Canada.

Corresponding Author

Anthony V Perruccio, PhD

Division of Orthopaedic Surgery

Toronto Western Hospital

399 Bathurst St.

East Wing, 1-427

Toronto, ON M5T 2S8

Phone: 416-603-5800 ext. 2017

Fax: 416-603-3437

Email: perrucci@uhnres.utoronto.ca

Grant support

This work was supported by an operating grant (number 77518) from the Canadian Institutes of Health Research. The funding sponsors had no role in the conduct, interpretation or dissemination of this work.

Competing interests

None of the authors have any competing interests in relation to this work.

Word count: 2,988

Table count: 5

Figure count: 1 
Objective: To determine whether symptomatic (painful/problematic) joints pre total knee replacement surgery (TKR), 1) influence pre and 12-month post-TKR patient-reported outcomes (pain, physical function, mood (fatigue, anxiety, and depression)); and 2) influence post-surgical pain and function mediated through mood.

Methods: 494 participants completed the identified patient-reported outcome measures pre- and 12-months post-TKR. Symptomatic (painful/problematic) joints were indicated on a homunculus pre-surgery. Covariate data included age, sex, educational attainment, BMI and comorbidity. Pre- and post-surgical outcome scores were regressed on symptomatic joint sites and covariates using linear regression analyses; post-surgical scores additionally were regressed on pre-surgery scores. Path analyses examined whether the effects of symptomatic joint sites on post-surgical pain and function were mediated through mood.

Results: Age range: $35-88$ years $($ mean $=65)$ with $65 \%$ female. Forty-six percent reported $\geq 4$ symptomatic joints (other than surgical knee). Pre- and post-surgery, worse outcome scores were observed with increasing joint count. Adjusted for covariates, individuals reporting ankle/feet/toes, neck and spine/lower-back had worse pre-surgery fatigue and anxiety. Adjusted for covariates and pre-surgery status, worse fatigue for neck and spine/lower back, and worse depression, pain and function for ankle/feet/toes and neck were observed post-surgery. The influence of ankle/feet/toes on post-surgical pain and function was in part direct and partially mediated through depression. Full mediation was found for neck through fatigue, anxiety and depression and for spine/lower back through fatigue.

Conclusions: Findings suggest a comprehensive approach to OA management/care are warranted, and identify important associations between symptomatic joints and mood which negatively impact post-TKR pain and physical function. 
Significance and Innovations.

- Multiple symptomatic joints were highly prevalent in this OA total knee replacement population and were associated with worse patient-reported outcomes (pain, physical function, and mood (fatigue, anxiety and depression)) both pre- and post-TKR.

- Mood played an important mediating role between symptomatic joints and post-TKR pain and physical function.

- These findings may help explain some of the variability observed in post-TKR outcomes across patients and suggests a holistic approach to OA management is warranted.

- Knowledge that a patient has multiple symptomatic joint involvement prior to surgery may be used to educate the patient, allowing for more realistic expectations to be set and the need for adoption of self-management strategies, pre- and post-surgery, to be more apparent. 
When conservative treatment fails for hip or knee osteoarthritis (OA), total joint replacement (TJR) is an elective surgical option that can provide significant pain relief and improved function with proven cost-effectiveness ${ }^{1 ; 2}$. Patient-reported outcomes are indispensable in evaluating $\mathrm{TJR}^{2}$. By far, the focus of patient-reported outcomes studies in TJR have been on pain and function; not surprising as these are the key indicators for surgery ${ }^{1 ; 3 ; 4}$.

Several literature reviews have reported on the determinants of patient-reported pain and physical function outcomes for primary TJR for OA. Evaluating demographic and socioeconomic characteristics, and pre-operative comorbidity and pain and function as determinants of post-operative pain and function has been the predominant focus ${ }^{1 ; 3 ; 4}$. Patient expectations and pre-operative psychological status also have been assessed as predictors of post-operative pain and function and health-related quality of life generally ${ }^{5-9}$. While TJR has been shown to be highly effective for relieving the pain and ameliorating the limited function associated with hip and knee OA, significant variability in the degree of improvement in these outcomes following primary TJR have been noted ${ }^{3 ; 4 ; 10}$. Generally, the extent to which these factors have explained post-TJR outcomes has been modest ${ }^{1}$.

OA can simultaneously affect multiple joints in the body ${ }^{11}$. Yet, the influence of multiple symptomatic joints is not routinely considered in OA studies which enroll patients or participants based on OA in a specific joint. This is particularly the case for studies assessing patient-reported outcomes in cohorts undergoing total joint replacement (TJR) for OA. Since multiple joints can be affected in OA, and given the complex involvement of many joints in lower extremity function, we posit that the presence of multiple symptomatic joints in TJR populations negatively influences lower extremity pain and function, and thus potentially may explain some of the 
variability in these post-surgical patient-reported outcomes. In other words, the surgical intervention on the hip or knee is but one component in the management of lower extremity symptoms and limited function associated with the disease.

Several studies also have identified an association between poorer pre-TJR mood (fatigue, anxiety, and/or depression) and poorer post-surgery outcomes ${ }^{5-9}$. Additionally, studies have generally identified an association (some suggest bidirectional), between mood and levels of pain and physical function, including in $\mathrm{OA}^{8 ; 12-14}$. Thus, we further posit that the presence of multiple symptomatic joints may influence pre-and post-surgical levels of pain and function in part through mood.

In this study, we consider the influence of specific symptomatic joints in a total knee replacement (TKR) cohort on 1) pre-surgery pain and function; 2) pre-surgery mood; 3) postsurgery levels of pain and function and mood; and 4) examine whether the influence of symptomatic joints on post-surgical pain and function are mediated through mood. 


\section{PATIENTS AND METHODS}

Individuals undergoing primary unilateral TJR for knee OA were recruited from four Toronto, Canada academic hospitals. Eligibility criteria included 18 years of age or older and ability to read and comprehend English. Individuals having surgery for other than osteoarthritis or revision-arthroplasty were ineligible.

The study was approved by the University Health Network Research Ethics Board (REB) and the REB of each participating institution. Written informed consent was obtained from all study participants. Mailed health questionnaires were completed pre-surgery and at 12 months post-surgery.

Painful joints. Prior to surgery only, study participants were asked to indicate on a homunculus all joints that were painful or problematic and affected by arthritis.

Pain on activity and limitations in physical function were assessed with the Western Ontario McMaster University Osteoarthritis Outcome Index (Likert version 3.0) (WOMAC) ${ }^{15}$. The WOMAC is one of the most often used lower extremity patient-reported pain and function measures used in hip and knee TJR. The measure assesses the frequency and extent of pain during activities such as 'walking on a flat surface' and 'going up/down stairs' and assesses individuals' ability to move around and look after themselves, eliciting the degree of difficulty experienced due to their knee. The measures have documented reliability, validity and responsiveness in $\mathrm{TKR}^{15 ; 16}$. Pain scores can range from 0-20 and physical function from 0-68; higher scores indicate worse status.

Fatigue was assessed with the Profile of Mood States fatigue subscale ${ }^{17}$. The POMS is a frequently used measure of fatigue in the literature and has been used to study fatigue in a range 
of chronic conditions. The POMS has documented validity ${ }^{18}$ with scores ranging from $0-20$; higher scores indicate worse status.

Anxiety and Depression were captured with the Hospital Anxiety and Depression Scale ${ }^{19}$. The HADS has been widely used in outpatient populations, and the reliability of each subscale is sufficient for group comparisons in multiple populations ${ }^{20}$.

Pain, limitations in physical function, fatigue, anxiety and depression measures were administered at both time points. Collected pre-surgery were: Comorbidity (individuals responded yes/no to a list of 14 medical problems identified in the Self-Administered Comorbidity Questionnaire ${ }^{21}$ ), age at surgery, sex, level of education ( $\leq$ high-school, $\geq$ postsecondary), and height and weight, used to calculate body mass index (overweight $(25 \leq \mathrm{BMI}<30)$; obese $(\mathrm{BMI} \geq 30))$.

Analyses

The demographic, obesity, comorbidity and painful joint location profile of the sample was described and tetrachoric correlations between joint sites were calculated. As well, pre-surgery and 12-month post-surgery scores for all study measures were documented for the overall sample and by symptomatic joint count (other than the surgical knee): 0 (i.e. surgical knee only); 1 to 3 ; and 4 or more. A test for trend for each study measure was conducted both pre- and post-surgery by symptomatic joint count. Linear regression analyses were used to examine the influence of painful joint involvement (by location) on pre-surgery and 12-month post-surgery scores for each study measure. Regression models were adjusted by age at surgery, sex, level of education, overweight and obesity, and comorbidity count. For the models where the post-surgical score was the dependent variable, pre-surgery scores for the respective measures were also included as 
predictors. As multiple comparisons were undertaken, Bonferroni adjustment, including a correction for correlated outcomes, of critical p-values was utilized for the linear regressions. With this adjustment, p-values $\leq 0.027$ were considered statistically significant, and the z-value for 2-sided testing equaled 2.21.

To test our hypotheses, and dependent on whether the linear regressions results suggested that painful/problematic joints influenced pre- and post-surgical pain, physical function and mood scores, path analyses were undertaken to assess the possibility that the effects of presurgery painful/problematic joints on post-surgical pain and physical function were mediated through mood. Figure 1 diagrammatically presents the hypothesized mediated model. While all models included age, sex, level of education, overweight/obese, and comorbidity count, these are not shown in the diagram. Two models were assessed such that the influences of painful/problematic joint sites on post-surgery pain (Model 1) and physical function (Model 2) scores were specified both as direct and indirect (through post-surgery fatigue, anxiety and depression) effects. Direct effects from pre-surgery scores to respective post-surgery scores were specified for all measures. Additionally, the influence of pre-surgery mood on post-surgery pain and physical function was specified as both direct and indirect (through post-surgery mood). Different indices provide different information about model fit. Five indices were considered: model $\chi^{2}$, root mean square error of approximation (RMSEA), comparative fit index (CFI), Tucker-Lewis index (TLI) and the standardized root mean square residual (SRMR). Good fit was supported by a non-significant $\chi^{2}$ (i.e. $p>0.05$ ), and values $\leq 0.05, \geq 0.95, \geq 0.95$, and $\leq 0.08$, respectively. To identify potential focal areas of misfit in the model, standardized covariance residuals also were examined, with values $>2.58$ interpreted as misfit (i.e. significant residual). Analyses were carried out using SAS 9.2 for the linear regressions and Mplus 6.1 for the path 
analyses.

Sample size adequacy was assessed using two approaches suggested in the literature for structural equations modeling. The first was based on the requirement of at least five subjects per parameter to be estimated $^{22 ; 23}$. Based on our hypothesized path model, comprised of 67 parameters to be estimated, this would require an $n \geq 335$. The other approach was based on using the RMSEA as effect size. Specifically, it was based on a test of the null hypothesis of close fit $(\mathrm{RMSEA}=0.0$ for exact fit) versus the alternative hypothesis of not close fit (RMSEA of 0.05) $24 ; 25$. In our case, our $n$ provided power $=81.2 \%$ 


\section{RESULTS}

494 patients participated in the study and provided baseline data. Across study measures, a minimum of 435 provided 12-month data. Table 1 presents a description of the study sample. The majority of participants were female $(65 \%)$ and the mean age of the sample was 65 years, with ages ranging from 35 to 88 years. The majority of the sample reported greater than high school education and just less than half of the sample had a BMI value indicative of obesity. The vast majority $(85 \%)$ reported a painful joint other than their surgical knee on the homunculus, with nearly half the sample reporting four or more painful/problematic joints. The most frequently reported joint was the contralateral knee, followed by elbow/wrists/hands. One-third of the sample reported symptomatic ankles/feet/toes, and spine/lower back. One-fifth of the sample reported their neck as painful/problematic. Tetrachoric correlations between joint sites (data not shown) ranged from 0.06 to 0.6 , with the smallest between contralateral knee and hips and largest between neck and spine/lower back.

Pre-surgery and 12-month scores for the patient-reported outcomes are presented in Table 2 for the overall sample and by symptomatic (other than surgical knee) joint count; higher scores represent worse status. Statistically significant trends were observed, with lower scores (i.e. less pain and functional difficulties) among individuals who reported no joints other than their surgical knee and higher scores among those reporting 4 or more symptomatic joints. These trends were consistent for both the mood and knee-specific measures at all times.

Results from the linear regression analyses examining pre-surgery scores are presented in Table 3. Adjusted for age, sex, education, overweight/obese, comorbidity count, and all joint sites, individuals reporting foot/ankle/toes, neck, and spine/lower back had worse pre-surgery 
fatigue and/or anxiety scores compared to those not reporting these joint sites. Individuals reporting painful/problematic shoulders had worse pre-surgery scores for WOMAC pain.

From our second set of linear regressions, pre-surgery scores were found to be significantly associated with 12-month scores across all measures (Table 4). Consistently, higher pre-surgery scores predicted higher post-surgery scores; the magnitudes of the betas, however, are consistent with overall improvements over the 12-month recovery period for all measures. Adjusted for presurgery scores, individuals who reported ankle/feet/toes had worse post-surgery scores for depression and WOMAC pain and physical function. Individuals reporting painful/problematic neck had worse post-surgery scores for fatigue, depression and WOMAC pain and physical function. Finally, individuals reporting painful/problematic spine/lower back had worse scores for fatigue. The percent of variance explained for each of these post-surgical outcomes ranged from $27 \%$ to $45 \%$ for mood, and was $20 \%$ and $29 \%$ for WOMAC pain and physical function.

Although the magnitudes of the correlation coefficients were not suggestive of any high collinearity, variance inflation factors (VIF) for joint sites were nevertheless examined in the above linear regressions to ensure that multicollinearity was not a problem. The largest VIF encountered across all models (data not shown) was 1.39, far below accepted cutoff values of 10 and even more stringent cutoffs of $2.5^{26 ; 27}$, suggesting multicollinearity was not a concern.

Both path analytic models displayed very good overall model fit without localized areas of strain. For Model 1 (examining post-surgery WOMAC pain): $\operatorname{model} \chi^{2}=18.189$ $\left(\operatorname{Prob}\left(\chi_{15}^{2}>18.189\right)=0.2529\right), \operatorname{RMSEA}=0.023(\operatorname{Prob}(\operatorname{RMSEA} \leq 0.05)=0.904), \mathrm{CFI}=0.997$, TLI=0.986, SRMR=0.011 and standardized covariance residuals $<\mid \pm 1.81$. For Model 2 (examining post-surgery WOMAC physical function): $\operatorname{model} \chi^{2}=18.59\left(\operatorname{Prob}\left(\chi_{15}{ }^{2}>18.59\right)=\right.$ 0.2329), RMSEA=0.025 (Prob $(\mathrm{RMSEA} \leq 0.05)=0.895), \mathrm{CFI}=0.997, \mathrm{TLI}=0.985, \mathrm{SRMR}=0.010$, 
and standardized covariance residuals $<\mid \pm 1.81$.

Results from the path analyses (Table 5) indicated that the influence of ankle/feet/toes on post-surgical pain and physical function scores were partially direct and partially mediated through post-surgery depression. No other direct effects of joint sites on post-surgical pain and function were found to be significant. However, painful/problematic neck was found to be significantly associated with post-surgery levels of anxiety, depression and fatigue, and painful/problematic spine/lower back with post-surgical levels of fatigue (in all cases, reporting of the joint site was associated with worse scores). Post-surgical levels of depression and fatigue were in turn associated with post-surgical levels of pain and physical function (higher levels of depression and fatigue associated with worse pain and physical function), and improvement in depression scores was associated with better post-surgical pain levels. Thus, the results suggest the effects of ankle/feet/toes (partially) and neck and spine/lower back (fully) were mediated through mood. The percent of variance explained for post-surgical pain was $43.5 \%$ and $54 \%$ for physical function. 
DISCUSSION

Joint pain has been identified as an important determinant of overall health status and level of disability in population studies ${ }^{28-31}$. OA affects many joints, often in combination, yet the influence of multiple symptomatic joints has received limited attention in joint-specific OA cohorts, particularly TKR cohorts. The goal of this investigation was to determine whether the presence of painful/problematic joints pre-surgery influenced patient-reported outcomes prior to and following TKR for OA and to understand how multiple joint involvements might influence pain and physical functional status.

It was the norm, not the exception, in this knee OA cohort for multiple painful joints to be reported. Nearly half the sample reporting in excess of three joints other than the surgical knee, and at least one-third reported each of at least one upper and one lower extremity joint. When considering the influence of painful joints on post-surgical outcomes, the focus has been predominantly on the contralateral joint and on low back pain, and these influences have predominantly been examined in total hip replacement ${ }^{32-36}$. Consistently, painful symptoms in the contralateral joint and in the lower back have been associated with worse post-surgical pain and physical function status in these cohorts.

Our work points to a significant influence of specific symptomatic joints on post-TKR pain and function, including the ankle/feet/toes, spine/lower back and neck. Given that the WOMAC pain and physical function questions elicit responses for daily activities in which the feet and ankles play a critical role (e.g. walking on a flat surface), it is not surprising that poorer scores were observed for individuals reporting ankle/feet/toes as being painful or problematic. In a study examining activity levels following TKR, Dahm et al. reported that study participants cited other problematic joints as limiting their activity ${ }^{37}$. Of these, the hip, opposite knee and 
foot/ankle were most frequently cited. Our findings from the path analyses show the only joints which had direct effects on post-surgery pain and function scores were the ankle/feet/toes. Additionally, the influence of pain in these joints was found to be mediated through mood, particularly depression.

The association of upper extremity problematic joints, and particularly the neck, with lower extremity post-surgery pain and function in this cohort was not initially obvious. However, results from the path analyses revealed an important relationship between the reporting of neck and spine/lower back as painful/problematic and poorer mood status, and then through to lower extremity pain and function post-surgical scores. These effects were fully mediated through the mood indicators, either through anxiety (neck), depression (neck) or fatigue (neck and spine/back). Although previous studies have not considered such mediated path models in this population, these findings are consistent with studies identifying poorer psychological status as a risk factor for musculoskeletal pain and disability ${ }^{28 ; 38-41}$. Poorer pre-surgery psychological status or mood has been associated with worse pain and physical function status post-surgery 1;4;8;42. As well, a number of studies have reported an association between higher levels of anxiety, depression, and/or fatigue and poorer pain and physical function status, and suggested that these relationships may be bidirectional ${ }^{13}$. In a community sample of individuals with lower extremity OA, Hawker et al. similarly reported on the impact of pain on later depression and fatigue and subsequently on worsening pain ${ }^{12}$. Power et al. reported that individuals with lower extremity OA identified fatigue as both being influenced by and influencing later experiences of pain and disability ${ }^{14}$.

These associations may be a critical link, therefore, in understanding the variability observed among individuals with specific painful joint sites. The high prevalence of multiple symptomatic 
joints in this TKR population suggests that systemic effects may operational in OA, with negative consequences on lower extremity pain and function and overall indicators of mood. These findings support a more holistic approach to OA management ${ }^{43}$, with a view that joint replacement is but one part of the potential package of care and management. Conceivably, these findings highlight a need for OA-specialist care. Additionally, for the surgeon, knowledge that the patient has multiple painful joint involvement prior to surgery may be used to educate the patient, allowing for more realistic expectations to be set and the need for adoption of selfmanagement strategies, pre- and post-surgery, to be more apparent.

A limitation of this study is that it was limited to a knee OA cohort. Whether similar associations, frequency of multiple symptomatic joint involvement, and similar joint-specific prevalence estimates would be identified in other joint-specific OA cohorts is unclear. However, similarities in conclusions between studies of community samples with OA and our knee OA cohort suggest that similar patterns of effects may be operational. Also, our sample was limited to patients recruited from academic hospitals. We note, however, that a recent study ${ }^{44}$ compared patient-reported functional outcomes following primary TKR between surgeries performed in 5 academic and 5 community hospitals. Differences in pain and function and patient quality of life were not detected between the groups at any of the study time points. This suggests that postsurgical trajectories of functional status and quality of life in the present sample are likely to be typical of primary TKR outcomes more generally.

Multiple symptomatic joint involvement in OA is well established. Our findings suggest a comprehensive approach to $\mathrm{OA}$ and musculoskeletal comorbidity management and care are warranted, and identify important associations between painful joints and mood which ultimately negatively impact post-surgical TKR outcomes, and overall health-related quality of life. 
Reference List

(1) Jones CA, Beaupre LA, Johnston DW, Suarez-Almazor ME. Total joint arthroplasties: current concepts of patient outcomes after surgery. Rheum Dis Clin North Am 2007; 33(1):71-86.

(2) Jones DL, Westby MD, Greidanus N, Johanson NA, Krebs DE, Robbins L et al. Update on hip and knee arthroplasty: current state of evidence. Arthritis Rheum 2005; 53(5):772-780.

(3) Ethgen O, Bruyere O, Richy F, Dardennes C, Reginster JY. Health-related quality of life in total hip and total knee arthroplasty. A qualitative and systematic review of the literature. J Bone Joint Surg Am 2004; 86-A(5):963-974.

(4) Santaguida PL, Hawker GA, Hudak PL, Glazier R, Mahomed NN, Kreder HJ et al. Patient characteristics affecting the prognosis of total hip and knee joint arthroplasty: a systematic review. Can J Surg 2008; 51(6):428-436.

(5) Ayers DC, Franklin PD, Ploutz-Snyder R, Boisvert CB. Total knee replacement outcome and coexisting physical and emotional illness. Clin Orthop Relat Res 2005; 440:157-161.

(6) Lingard EA, Riddle DL. Impact of psychological distress on pain and function following knee arthroplasty. J Bone Joint Surg Am 2007; 89(6):1161-1169.

(7) Perruccio AV, Badley EM, Hogg-Johnson S, Davis AM. Characterizing self-rated health during a period of changing health status. Soc Sci Med 2010; 71(9):1636-1643.

(8) Perruccio AV, Davis AM, Hogg-Johnson S, Badley EM. The importance of self-rated health and mental well-being in predicting health outcomes following total joint replacement surgery for osteoarthritis. Arthritis Care Res (Hoboken ) 2011.

(9) Rolfson O, Dahlberg LE, Nilsson JA, Malchau H, Garellick G. Variables determining outcome in total hip replacement surgery. J Bone Joint Surg Br 2009; 91(2):157-161.

(10) Woolhead GM, Donovan JL, Dieppe PA. Outcomes of total knee replacement: a qualitative study. Rheumatology (Oxford) 2005; 44(8):1032-1037.

(11) Sharma L, Kapoor D, Issa S. Epidemiology of osteoarthritis: an update. Curr Opin Rheumatol 2006; 18(2):147-156.

(12) Hawker GA, Gignac MA, Badley E, Davis AM, French MR, Li Y et al. A longitudinal study to explain the pain-depression link in older adults with osteoarthritis. Arthritis Care Res (Hoboken ) 2011; 63(10):1382-1390.

(13) Katon W, Lin EH, Kroenke K. The association of depression and anxiety with medical symptom burden in patients with chronic medical illness. Gen Hosp Psychiatry 2007; 29(2):147-155.

(14) Power JD, Badley EM, French MR, Wall AJ, Hawker GA. Fatigue in osteoarthritis: a qualitative study. BMC Musculoskelet Disord 2008; 9:63.

(15) Bellamy N, Buchannan WW, Goldsmith CH, Campbell J, Stitt LW. Validation study of WOMAC: a health status instrument for measuring clinically-important patient-relevant 
outcomes following total hip or knee arthroplasy in osteoarthritis. J Orthop Rheumatol 1988; 15:95-108.

(16) McConnell S, Kolopack P, Davis AM. The Western Ontario and McMaster Universities Osteoarthritis Index (WOMAC): a review of its utility and measurement properties. Arthritis Rheum 2001; 45(5):453-461.

(17) McNair DM, Heuchert JWP. POMS (Profile of Mood States) Technical Update and Scoring Sheet. 2003.

(18) Nyenhuis DL, Yamamoto C, Luchetta T, Terrien A, Parmentier A. Adult and geriatric normative data and validation of the profile of mood states. J Clin Psychol 1999; 55(1):79-86.

(19) Zigmond AS, Snaith RP. The hospital anxiety and depression scale. Acta Psychiatr Scand 1983; 67(6):361-370.

(20) Herrmann C. International experiences with the Hospital Anxiety and Depression Scale--a review of validation data and clinical results. J Psychosom Res 1997; 42(1):17-41.

(21) Sangha O, Stucki G, Liang MH, Fossel AH, Katz JN. The Self-Administered Comorbidity Questionnaire: a new method to assess comorbidity for clinical and health services research. Arthritis Rheum 2003; 49(2):156-163.

(22) Bentler PM, Chou CP. Practical Issues in Structural Modeling. Sociological Methods \& Research 1987; 16(1):78-117.

(23) Hatcher L. A Step-by-Step Approach to Using the SAS System for Factor analysis and Structural Equation Modeling. Cary, NC: SAS Institute, 1994.

(24) MacCallum R, Lee T, Browne MW. The Issue of Isopower in Power Analysis for Tests of Structural Equation Models. Structural Equation Modeling: A Multidisciplinary Journal 2010; 17(1):23-41.

(25) MacCallum RC, Browne MW, Sugawara HM. Power analysis and determination of sample size for covariance structure modeling. Psychological Methods 1996; 1(2):130-149.

(26) Allison PD. What Can Be Done About Multicollinearity. Multiple regression: A Primer. Thousand Oaks, CA: Pine Forge Press, Inc., 1999.

(27) Norman G, Streiner D. Biostatistics: The Bare Essentials. 2 ed. Toronto: BC Decker, 2000.

(28) Dawson J, Linsell L, Zondervan K, Rose P, Randall T, Carr A et al. Epidemiology of hip and knee pain and its impact on overall health status in older adults. Rheumatology (Oxford) 2004; 43(4):497-504.

(29) Leveille SG, Ling S, Hochberg MC, Resnick HE, Bandeen-Roche KJ, Won A et al. Widespread musculoskeletal pain and the progression of disability in older disabled women. Ann Intern Med 2001; 135(12):1038-1046.

(30) Gooberman-Hill R, Woolhead G, Mackichan F, Ayis S, Williams S, Dieppe P. Assessing chronic joint pain: lessons from a focus group study. Arthritis Rheum 2007; 57(4):666-671. 
(31) Peat G, Thomas E, Wilkie R, Croft P. Multiple joint pain and lower extremity disability in middle and old age. Disabil Rehabil 2006; 28(24):1543-1549.

(32) Nilsdotter AK, Petersson IF, Roos EM, Lohmander LS. Predictors of patient relevant outcome after total hip replacement for osteoarthritis: a prospective study. Ann Rheum Dis 2003; 62(10):923-930.

(33) Novicoff WM, Rion D, Mihalko WM, Saleh KJ. Does concomitant low back pain affect revision total knee arthroplasty outcomes? Clin Orthop Relat Res 2009; 467(10):2623-2629.

(34) Quintana JM, Escobar A, Aguirre U, Lafuente I, Arenaza JC. Predictors of health-related qualityof-life change after total hip arthroplasty. Clin Orthop Relat Res 2009; 467(11):2886-2894.

(35) Savaridas T, Elton RE, Brenkel IJ, Ballantyne JA. Hip arthroplasty patient-reported outcome unaffected by back pain in women. European Journal of Orthopaedic Surgery \& Traumatology 2011; 21(4):269-273.

(36) Scott CE, Howie CR, MacDonald D, Biant LC. Predicting dissatisfaction following total knee replacement: a prospective study of 1217 patients. J Bone Joint Surg Br 2010; 92(9):1253-1258.

(37) Dahm DL, Barnes SA, Harrington JR, Sayeed SA, Berry DJ. Patient-reported activity level after total knee arthroplasty. J Arthroplasty 2008; 23(3):401-407.

(38) Adamson J, Ebrahim S, Dieppe P, Hunt K. Prevalence and risk factors for joint pain among men and women in the West of Scotland Twenty-07 study. Ann Rheum Dis 2006; 65(4):520-524.

(39) Cecchi F, Mannoni A, Molino-Lova R, Ceppatelli S, Benvenuti E, Bandinelli S et al. Epidemiology of hip and knee pain in a community based sample of Italian persons aged 65 and older. Osteoarthritis Cartilage 2008; 16(9):1039-1046.

(40) Felson DT, Lawrence RC, Dieppe PA, Hirsch R, Helmick CG, Jordan JM et al. Osteoarthritis: new insights. Part 1: the disease and its risk factors. Ann Intern Med 2000; 133(8):635-646.

(41) Thumboo J, Chew LH, Lewin-Koh SC. Socioeconomic and psychosocial factors influence pain or physical function in Asian patients with knee or hip osteoarthritis. Ann Rheum Dis 2002; 61(11):1017-1020.

(42) Gandhi R, Dhotar H, Razak F, Tso P, Davey JR, Mahomed NN. Predicting the longer term outcomes of total knee arthroplasty. Knee 2010; 17(1):15-18.

(43) Rosemann T, Wensing M, Joest K, Backenstrass M, Mahler C, Szecsenyi J. Problems and needs for improving primary care of osteoarthritis patients: the views of patients, general practitioners and practice nurses. BMC Musculoskelet Disord 2006; 7:48.

(44) Gandhi R, Tso P, Davis A, Mahomed NN. Outcomes of total joint arthroplasty in academic versus community hospitals. Can J Surg 2009; 52(5):413-416. 
Table 1. Sample descriptives*.

\begin{tabular}{|c|c|}
\hline & Mean (range) or Proportion \\
\hline Age & $64.9(35,88)$ \\
\hline Sex: Female & $65.4 \%$ \\
\hline Education: $\leq$ high school & $40.7 \%$ \\
\hline \multicolumn{2}{|l|}{ Body mass index: } \\
\hline overweight $(25 \leq \mathrm{BMI}<30)$ & $37.9 \%$ \\
\hline obese $(\mathrm{BMI} \geq 30)$ & $45.3 \%$ \\
\hline Comorbidity count & $1.5(0,6)$ \\
\hline \multicolumn{2}{|l|}{ Painful/problematic joints } \\
\hline Surgical joint only & $15.2 \%$ \\
\hline \multicolumn{2}{|l|}{ Not including surgical joint } \\
\hline Count & $5.1(1,19)$ \\
\hline 1 & $16.6 \%$ \\
\hline 2 & $12.8 \%$ \\
\hline 3 & $9.9 \%$ \\
\hline $4+$ & $45.5 \%$ \\
\hline Contralateral knee & $57.1 \%$ \\
\hline Elbow/Wrists/Hands & $49.0 \%$ \\
\hline Ankle/Feet/Toes & $36.0 \%$ \\
\hline Spine/lower back & $30.6 \%$ \\
\hline Shoulders & $29.4 \%$ \\
\hline Hips & $24.7 \%$ \\
\hline Neck & $21.7 \%$ \\
\hline
\end{tabular}

${ }^{*} N$ ranges from 471 to 494 for individual characteristic responses. 
John Wiley \& Sons, Inc. 
Table 2 . Health measure scores* ${ }^{*}$, pre-surgery and 12-months post-surgery; overall and by symptomatic joint count.

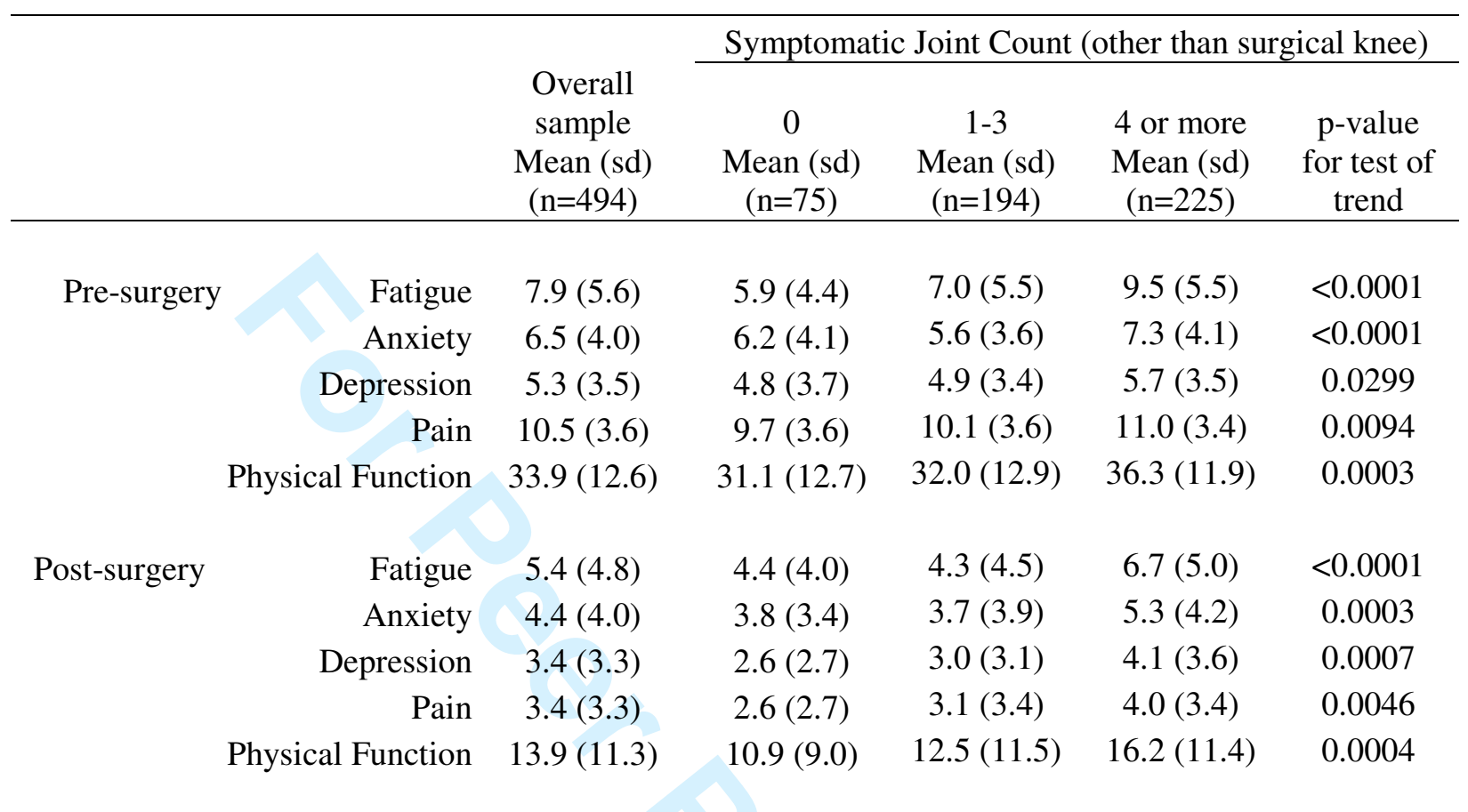

*Higher scores indicate worse status.

$\dagger$ Possible score range: Fatigue (0-20); Anxiety (0-21); Depression (0-21); WOMAC pain (0-20) and physical function (0-68). 
Table 3. Linear regression results; outcome: pre-surgery patient-reported outcome score (statistically significant effects are bolded)*

\begin{tabular}{|c|c|c|c|c|c|}
\hline \multirow[b]{3}{*}{ Predictors } & \multicolumn{5}{|c|}{ Model Outcome } \\
\hline & Fatigue & Anxiety & Depression & Pain & $\begin{array}{l}\text { Physical } \\
\text { Function }\end{array}$ \\
\hline & \multicolumn{5}{|c|}{ Beta (Confidence Interval) } \\
\hline Age & $\begin{array}{c}\mathbf{- 0 . 1 1} \\
(-0.16,-0.05)\end{array}$ & $\begin{array}{c}\mathbf{- 0 . 0 9} \\
(-0.13,-0.05)\end{array}$ & $\begin{array}{c}\mathbf{- 0 . 0 9} \\
(-0.13,-0.06)\end{array}$ & $\begin{array}{c}\mathbf{- 0 . 1 0} \\
(-0.14,-0.07)\end{array}$ & $\begin{array}{c}\mathbf{- 0 . 1 8} \\
(-0.31,-0.06)\end{array}$ \\
\hline Gender (ref: female) & $\begin{array}{c}\mathbf{- 1 . 3 7} \\
(-2.55,-0.19)\end{array}$ & $\begin{array}{c}\mathbf{- 0 . 8 5} \\
(-1.68,-0.01)\end{array}$ & $\begin{array}{c}-0.61 \\
(-1.36,0.13)\end{array}$ & $\begin{array}{c}\mathbf{- 1 . 0 8} \\
(-1.82,-0.35)\end{array}$ & $\begin{array}{c}\mathbf{- 3 . 4 7} \\
(-6.08,-0.86)\end{array}$ \\
\hline $\begin{array}{l}\text { Education } \\
\qquad \text { (ref:>high school) }\end{array}$ & $\begin{array}{c}1.17 \\
(-0.02,2.36)\end{array}$ & $\begin{array}{c}\mathbf{1 . 4 7} \\
(0.64,2.31)\end{array}$ & $\begin{array}{c}0.69 \\
(-0.06,1.44)\end{array}$ & $\begin{array}{c}\mathbf{1 . 1 8} \\
(0.44,1.92)\end{array}$ & $\begin{array}{c}\mathbf{4 . 8 3} \\
(2.22,7.44)\end{array}$ \\
\hline BMI (ref: normal) & & & & & \\
\hline Overweight & $\begin{array}{c}-0.42 \\
(-1.99,1.16)\end{array}$ & $\begin{array}{c}-0.38 \\
(-1.50,0.74)\end{array}$ & $\begin{array}{c}-0.01 \\
(-1.01,0.99)\end{array}$ & $\begin{array}{c}-0.13 \\
(-1.13,0.86)\end{array}$ & $\begin{array}{c}1.69 \\
(-1.83,5.20)\end{array}$ \\
\hline Obese & $\begin{array}{c}1.52 \\
(-0.04,3.09)\end{array}$ & $\begin{array}{c}0.39 \\
(-0.72,1.50)\end{array}$ & $\begin{array}{c}\mathbf{1 . 0 7} \\
(0.08,2.06)\end{array}$ & $\begin{array}{c}0.98 \\
(-0.01,1.96)\end{array}$ & $\begin{array}{c}\mathbf{5 . 7 8} \\
(2.30,9.25)\end{array}$ \\
\hline Comorbidity count & $\begin{array}{c}0.08 \\
(-0.37,0.53)\end{array}$ & $\begin{array}{c}0.29 \\
(-0.03,0.61)\end{array}$ & $\begin{array}{c}0.15 \\
(-0.14,0.43)\end{array}$ & $\begin{array}{c}0.23 \\
(-0.05,0.51)\end{array}$ & $\begin{array}{c}\mathbf{1 . 2 3} \\
(0.24,2.22)\end{array}$ \\
\hline Contralateral Knee & $\begin{array}{c}-0.15 \\
(-1.27,0.97)\end{array}$ & $\begin{array}{c}-0.35 \\
(-1.14,0.44)\end{array}$ & $\begin{array}{c}-0.16 \\
(-0.87,0.54)\end{array}$ & $\begin{array}{c}0.37 \\
(-0.33,1.07)\end{array}$ & $\begin{array}{c}1.09 \\
(-1.39,3.56)\end{array}$ \\
\hline Ankle/Feet/Toes & $\begin{array}{c}\mathbf{1 . 4 5} \\
(0.20,2.69)\end{array}$ & $\begin{array}{c}0.85 \\
(-0.02,1.73)\end{array}$ & $\begin{array}{c}0.04 \\
(-0.75,0.82)\end{array}$ & $\begin{array}{c}-0.03 \\
(-0.80,0.75)\end{array}$ & $\begin{array}{c}0.57 \\
(-2.17,3.31)\end{array}$ \\
\hline Hips & $\begin{array}{c}0.39 \\
(-0.93,1.70)\end{array}$ & $\begin{array}{c}-0.27 \\
(-1.20,0.66)\end{array}$ & $\begin{array}{c}0.21 \\
(-0.62,1.04)\end{array}$ & $\begin{array}{c}0.07 \\
(-0.75,0.89)\end{array}$ & $\begin{array}{c}-0.02 \\
(-2.92,2.89)\end{array}$ \\
\hline Elbow/Wrists/Hands & $\begin{array}{c}0.83 \\
(-0.37,2.04)\end{array}$ & $\begin{array}{c}0.43 \\
(-0.42,1.27)\end{array}$ & $\begin{array}{c}0.03 \\
(-0.73,0.78)\end{array}$ & $\begin{array}{c}-0.21 \\
(-0.95,0.54)\end{array}$ & $\begin{array}{c}-0.55 \\
(-3.19,2.10)\end{array}$ \\
\hline Neck & $\begin{array}{c}1.90 \\
(0.42,3.39)\end{array}$ & $\begin{array}{c}\mathbf{1 . 0 6} \\
(0.01,2.11)\end{array}$ & $\begin{array}{c}0.60 \\
(-0.34,1.54)\end{array}$ & $\begin{array}{c}0.04 \\
(-0.88,0.96)\end{array}$ & $\begin{array}{c}1.10 \\
(-2.18,4.38)\end{array}$ \\
\hline Shoulder & $\begin{array}{c}-0.42 \\
(-1.79,0.95)\end{array}$ & $\begin{array}{c}-0.36 \\
(-1.33,0.61)\end{array}$ & $\begin{array}{c}0.09 \\
(-0.78,0.96)\end{array}$ & $\begin{array}{c}\mathbf{1 . 0 0} \\
(0.14,1.85)\end{array}$ & $\begin{array}{c}2.63 \\
(-0.39,5.66)\end{array}$ \\
\hline Spine/lower back & $\begin{array}{c}1.71 \\
(0.33,3.09)\end{array}$ & $\begin{array}{c}\mathbf{0 . 9 7} \\
(0.01,1.94)\end{array}$ & $\begin{array}{c}0.71 \\
(-0.15,1.58)\end{array}$ & $\begin{array}{c}0.47 \\
(-0.38,1.33)\end{array}$ & $\begin{array}{c}2.25 \\
(-0.76,5.26)\end{array}$ \\
\hline $\begin{array}{l}\text { Explained variance } \\
\left(\mathrm{R}^{2}(\%)\right)\end{array}$ & 20.1 & 16.5 & 14.0 & 20.3 & 19.2 \\
\hline
\end{tabular}

*Higher outcome score indicates worse status. 
Table 4. Linear regression results; outcome: post-surgery patient-reported outcome score (statistically significant effects are bolded)*

\begin{tabular}{|c|c|c|c|c|c|}
\hline \multirow[b]{3}{*}{ Predictors } & \multicolumn{5}{|c|}{ Model Outcome } \\
\hline & Fatigue & Anxiety & Depression & Pain & Phys. Func. \\
\hline & \multicolumn{5}{|c|}{ Beta (Confidence Interval) } \\
\hline Age & $\begin{array}{c}0.00 \\
(-0.05,0.06)\end{array}$ & $\begin{array}{c}0.00 \\
(-0.04,0.04)\end{array}$ & $\begin{array}{c}0.01 \\
(-0.02,0.04)\end{array}$ & $\begin{array}{c}0.02 \\
(-0.02,0.06)\end{array}$ & $\begin{array}{c}0.11 \\
(-0.00,0.23)\end{array}$ \\
\hline Gender (ref: female) & $\begin{array}{c}0.38 \\
(-0.66,1.42)\end{array}$ & $\begin{array}{c}0.56 \\
(-0.17,1.29)\end{array}$ & $\begin{array}{c}0.49 \\
(-0.16,1.14)\end{array}$ & $\begin{array}{c}0.32 \\
(-0.41,1.05)\end{array}$ & $\begin{array}{c}1.13 \\
(-1.22,3.48)\end{array}$ \\
\hline $\begin{array}{l}\text { Education } \\
\text { (ref:>high school) }\end{array}$ & $\begin{array}{c}0.37 \\
(-0.72,1.45)\end{array}$ & $\begin{array}{c}0.38 \\
(-0.39,1.15)\end{array}$ & $\begin{array}{c}0.27 \\
(-0.40,0.94)\end{array}$ & $\begin{array}{c}0.18 \\
(-0.57,0.93)\end{array}$ & $\begin{array}{c}0.60 \\
(-1.84,3.05)\end{array}$ \\
\hline BMI (ref: normal) & & & & & \\
\hline Overweight & $\begin{array}{c}-1.17 \\
(-2.55,0.22)\end{array}$ & $\begin{array}{c}\mathbf{- 1 . 2 6} \\
(-2.23,-0.28)\end{array}$ & $\begin{array}{c}-0.49 \\
(-1.36,0.37)\end{array}$ & $\begin{array}{c}-0.77 \\
(-1.74,0.20)\end{array}$ & $\begin{array}{c}-1.75 \\
(-4.85,1.35)\end{array}$ \\
\hline Obese & $\begin{array}{c}-0.67 \\
(-2.05,0.70)\end{array}$ & $\begin{array}{c}-0.90 \\
(-1.86,0.06)\end{array}$ & $\begin{array}{c}-0.40 \\
(-1.26,0.46)\end{array}$ & $\begin{array}{c}-0.73 \\
(-1.69,0.24)\end{array}$ & $\begin{array}{c}-1.43 \\
(-4.55,1.68)\end{array}$ \\
\hline Comorbidity count & $\begin{array}{c}0.27 \\
(-0.13,0.67)\end{array}$ & $\begin{array}{c}0.16 \\
(-0.12,0.45)\end{array}$ & $\begin{array}{c}\mathbf{0 . 3 7} \\
(0.12,0.62)\end{array}$ & $\begin{array}{c}0.07 \\
(-0.21,0.35)\end{array}$ & $\begin{array}{c}0.29 \\
(-0.62,1.19)\end{array}$ \\
\hline Contralateral Knee & $\begin{array}{c}-0.07 \\
(-1.05,0.92)\end{array}$ & $\begin{array}{c}0.20 \\
(-0.49,0.89)\end{array}$ & $\begin{array}{c}0.16 \\
(-0.46,0.77)\end{array}$ & $\begin{array}{c}-0.09 \\
(-0.77,0.59)\end{array}$ & $\begin{array}{c}-0.66 \\
(-2.86,1.55)\end{array}$ \\
\hline Ankle/Feet/Toes & $\begin{array}{c}0.12 \\
(-0.98,1.23)\end{array}$ & $\begin{array}{c}0.21 \\
(-0.56,0.98)\end{array}$ & $\begin{array}{c}\mathbf{0 . 7 3} \\
(0.04,1.41)\end{array}$ & $\begin{array}{c}\mathbf{1 . 2 4} \\
(0.48,2.00)\end{array}$ & $\begin{array}{c}\mathbf{3 . 1 4} \\
(0.69,5.59)\end{array}$ \\
\hline Hips & $\begin{array}{c}0.04 \\
(-1.14,1.21)\end{array}$ & $\begin{array}{c}0.00 \\
(-0.82,0.83)\end{array}$ & $\begin{array}{c}-0.10 \\
(-0.83,0.64)\end{array}$ & $\begin{array}{c}0.33 \\
(-0.48,1.15)\end{array}$ & $\begin{array}{c}-0.50 \\
(-3.12,2.12)\end{array}$ \\
\hline Elbow/Wrists/Hands & $\begin{array}{c}0.20 \\
(-0.85,1.26)\end{array}$ & $\begin{array}{c}-0.03 \\
(-0.76,0.70)\end{array}$ & $\begin{array}{c}-0.13 \\
(-0.78,0.52)\end{array}$ & $\begin{array}{c}-0.35 \\
(-1.08,0.37)\end{array}$ & $\begin{array}{c}-0.41 \\
(-2.75,1.94)\end{array}$ \\
\hline Neck & $\begin{array}{c}1.37 \\
(0.04,2.69)\end{array}$ & $\begin{array}{c}0.87 \\
(-0.06,1.80)\end{array}$ & $\begin{array}{c}\mathbf{1 . 1 5} \\
(0.33,1.97)\end{array}$ & $\begin{array}{c}\mathbf{1 . 0 7} \\
(0.17,1.98)\end{array}$ & $\begin{array}{c}\mathbf{3 . 4 6} \\
(0.54,6.38)\end{array}$ \\
\hline Shoulder & $\begin{array}{c}0.36 \\
(-0.84,1.57)\end{array}$ & $\begin{array}{c}0.28 \\
(-0.57,1.13)\end{array}$ & $\begin{array}{c}0.21 \\
(-0.55,0.96)\end{array}$ & $\begin{array}{c}-0.69 \\
(-1.54,0.15)\end{array}$ & $\begin{array}{c}-0.28 \\
(-2.97,2.41)\end{array}$ \\
\hline Spine/lower back & $\begin{array}{c}\mathbf{1 . 2 3} \\
(0.001,2.46)\end{array}$ & $\begin{array}{c}0.18 \\
(-0.67,1.04)\end{array}$ & $\begin{array}{c}-0.03 \\
(-0.79,0.73)\end{array}$ & $\begin{array}{c}0.46 \\
(-0.38,1.31)\end{array}$ & $\begin{array}{c}1.83 \\
(-0.86,4.53)\end{array}$ \\
\hline Pre-surgery score & $\begin{array}{c}\mathbf{0 . 3 4} \\
(0.24,0.43)\end{array}$ & $\begin{array}{c}\mathbf{0 . 6 1} \\
(0.52,0.70)\end{array}$ & $\begin{array}{c}\mathbf{0 . 5 0} \\
(0.41,0.60)\end{array}$ & $\begin{array}{c}\mathbf{0 . 3 4} \\
(0.24,0.45)\end{array}$ & $\begin{array}{c}\mathbf{0 . 4 1} \\
(0.31,0.50)\end{array}$ \\
\hline $\begin{array}{l}\text { Explained variance } \\
\left(\mathrm{R}^{2}(\%)\right)\end{array}$ & 27.4 & 44.5 & 36.6 & 20.0 & 29.0 \\
\hline
\end{tabular}

*Higher outcome score indicates worse status. 
Table 5. Path analysis results (statistically significant effects are bolded).

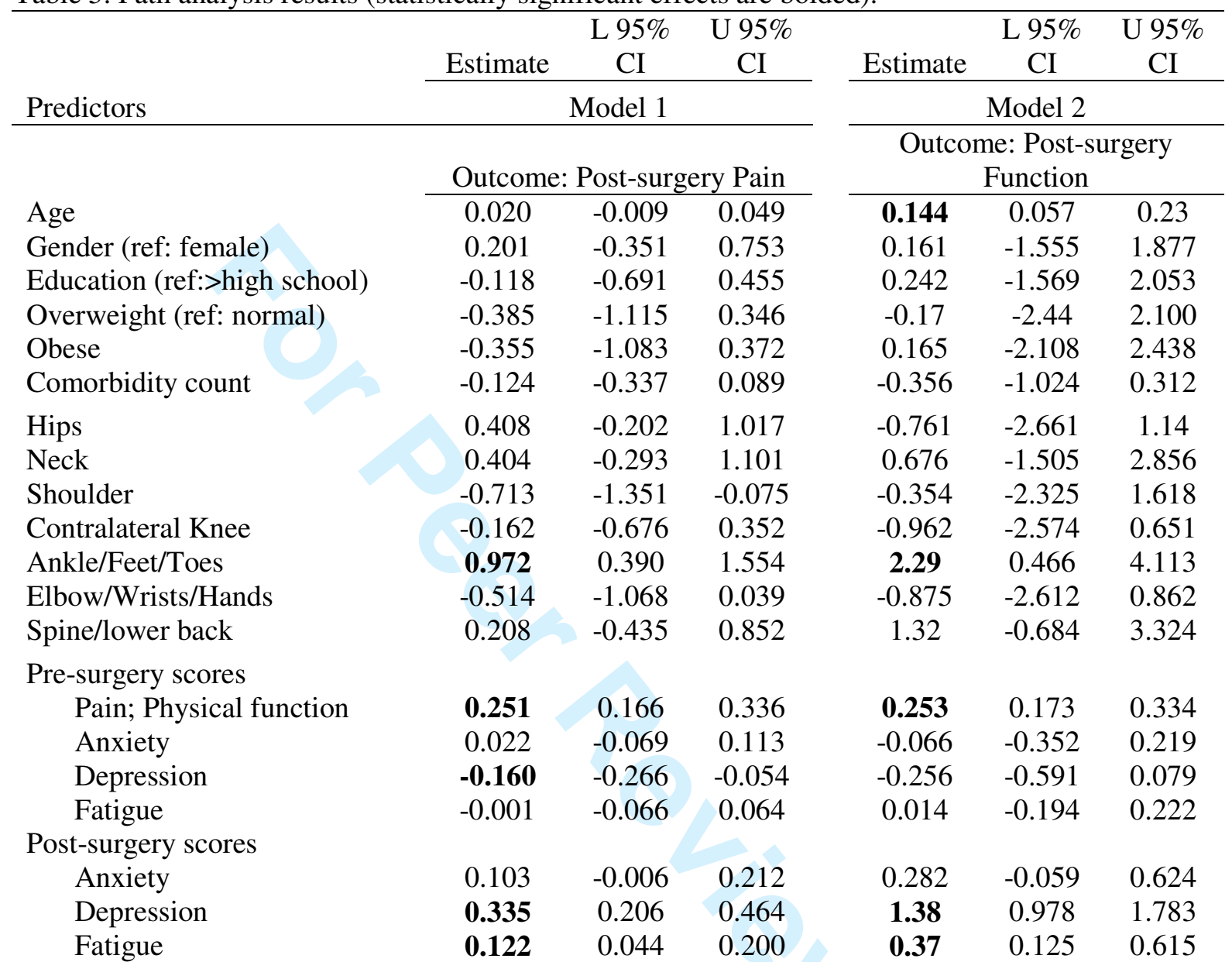

Hips

Neck

Shoulder

Contralateral Knee

Ankle/Feet/Toes

Elbow/Wrists/Hands

Spine/lower back
Dependant mediator variable:

\begin{tabular}{ccc} 
& Anxiety \\
\hline 0.052 & -0.69 & 0.795 \\
$\mathbf{0 . 8 9 9}$ & 0.071 & 1.728 \\
0.128 & -0.639 & 0.895 \\
0.169 & -0.447 & 0.786 \\
0.295 & -0.406 & 0.996 \\
-0.036 & -0.708 & 0.636 \\
0.196 & -0.56 & 0.952
\end{tabular}

Dependant mediator variable:

Hips

Neck

Shoulder

Contralateral Knee

Ankle/Feet/Toes

Elbow/Wrists/Hands

Spine/lower back

\begin{tabular}{ccc}
\multicolumn{3}{c}{ Depression } \\
\hline-0.069 & -0.711 & 0.573 \\
$\mathbf{1 . 0 9 5}$ & 0.374 & 1.816 \\
0.08 & -0.586 & 0.746 \\
0.119 & -0.416 & 0.654 \\
$\mathbf{0 . 6 8 5}$ & 0.078 & 1.291 \\
-0.138 & -0.72 & 0.444 \\
0.121 & -0.541 & 0.782
\end{tabular}

Dependant mediator variable: Anxiety

$\begin{array}{ccc}0.052 & -0.688 & 0.791 \\ \mathbf{0 . 8 6 7} & 0.039 & 1.694 \\ 0.221 & -0.538 & 0.979 \\ 0.177 & -0.438 & 0.792 \\ 0.285 & -0.415 & 0.985 \\ -0.062 & -0.733 & 0.608 \\ 0.145 & -0.606 & 0.896\end{array}$

Dependant mediator variable: Depression

$\begin{array}{ccc}-0.071 & -0.712 & 0.57 \\ \mathbf{1 . 0 6 5} & 0.343 & 1.787 \\ 0.164 & -0.495 & 0.824 \\ 0.142 & -0.394 & 0.678 \\ \mathbf{0 . 6 7 6} & 0.069 & 1.283 \\ -0.163 & -0.746 & 0.419 \\ 0.055 & -0.604 & 0.714\end{array}$


Hips

Neck

Shoulder

Contralateral Knee

Ankle/Feet/Toes

Elbow/Wrists/Hands

Spine/lower back

Explained Variance $\left(\mathrm{R}^{2}(\%)\right)$

Post-surgery_Pain; Phys Func

43.5

53.9

Post-surgery_Anxiety

44.5

44.7

Post-surgery_Depression

40.1

40.1

Post-surgery_Fatigue
31.4 
Figure 1. Hypothesized mediated model (paths of specific study interest are bolded)*.

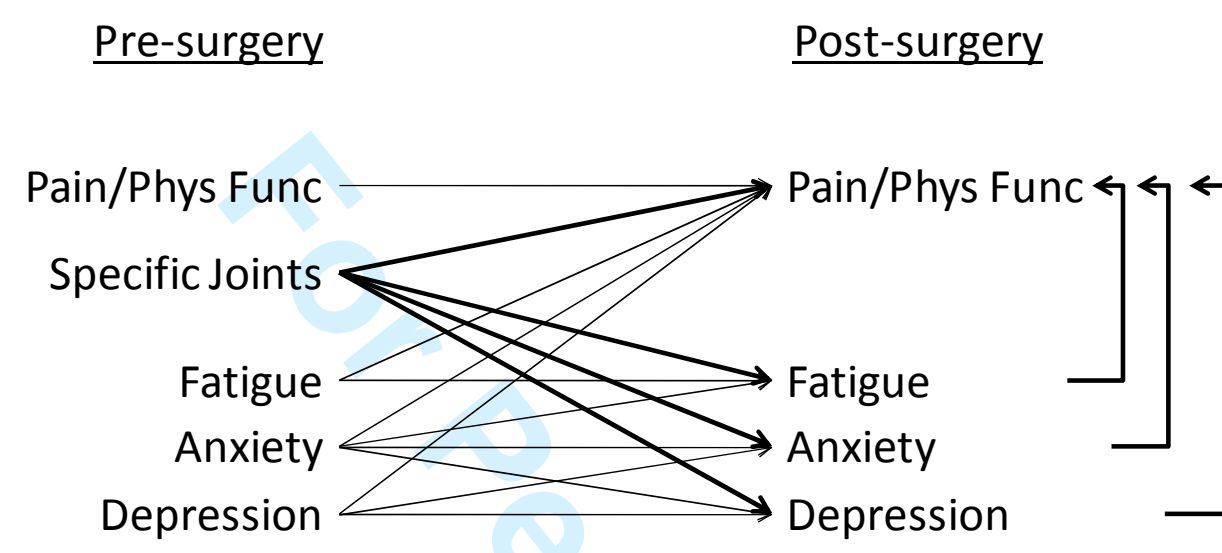

*All models adjusted for age, sex, level of education, overweight/obese, and comorbidity count (paths not shown). 